\title{
A budget impact analysis of parenteral iron treatments for iron deficiency anemia in the UK: reduced resource utilization with iron isomaltoside 1000
}

This article was published in the following Dove Press journal:

ClinicoEconomics and Outcomes Research

10 August 2017

Number of times this article has been viewed

\author{
Richard F Pollock' \\ Gorden Muduma ${ }^{2}$ \\ 'Ossian Health Economics and \\ Communications $\mathrm{GmbH}$, Basel, \\ Switzerland; ${ }^{2}$ Pharmacosmos $\mathrm{A} / \mathrm{S}$, \\ Holbaek, Denmark
}

Correspondence: Gorden Muduma Pharmacosmos A/S, Roervangsvej 30, DK-4300 Holbaek, Denmark Tel +447392080292

Email gmu@pharmacosmos.com
Background and aims: The reported prevalence of iron deficiency anemia (IDA) varies widely but estimates suggest that $3 \%$ of men and $8 \%$ of women have IDA in the UK. Parenteral iron is indicated for patients intolerant or unresponsive to oral iron or requiring rapid iron replenishment. This study evaluated differences in the cost of treating these patients with iron isomaltoside (Monofer ${ }^{\circledR}$, IIM) relative to other intravenous iron formulations.

Methods: A budget impact model was developed to evaluate the cost of using IIM relative to ferric carboxymaltose (Ferinject ${ }^{\circledR}$, FCM), low molecular weight iron dextran $\left(\right.$ Cosmofer ${ }^{\circledR}$, LMWID), and iron sucrose (Venofer ${ }^{\circledR}$, IS) in patients with IDA. To establish iron need, iron deficits were modeled using a simplified dosing table. The base case analysis was conducted over 1 year in patients with IDA with mean bodyweight of $82.4 \mathrm{~kg}$ (SD $22.5 \mathrm{~kg}$ ) and hemoglobin levels of $9.99 \mathrm{~g} / \mathrm{dL}$ (SD $1.03 \mathrm{~g} / \mathrm{dL}$ ) based on an analysis of patient characteristics in IDA trials. Costs were modeled using UK health care resource groups.

Results: Using IIM required 1.3 infusions to correct the mean iron deficit, compared with 1.3, 1.8, and 7.7 with LMWID, FCM, and IS, respectively. Patients using IIM required multiple infusions in $35 \%$ of cases, compared with $35 \%, 77 \%$, and $100 \%$ of patients with LMWID, FCM, and IS, respectively. Total costs were estimated to be GBP 451 per patient with IIM or LMWID, relative to GBP 594 with FCM (a GBP 143 or 24\% saving with IIM) or GBP 2,600 with IS (a GBP 2,149 or $83 \%$ saving with IIM).

Conclusion: Using IIM or LMWID in place of FCM or IS resulted in a marked reduction in the number of infusions required to correct iron deficits in patients with IDA. The reduction in infusions was accompanied by substantial reductions in cost relative to FCM and IS over 1 year. Keywords: iron deficiency anemia, iron, administration, intravenous, costs and cost analysis, Great Britain

\section{Introduction}

More than two billion people are affected by iron deficiency (ID) worldwide, and iron deficiency anemia (IDA) is the most common cause of anemia. ${ }^{1,2}$ While the reported prevalence of IDA varies widely, estimates suggest that $3 \%$ of men and $8 \%$ of women in the UK, and up to $2 \%$ of men and $5 \%$ of women in the US have IDA. ${ }^{3,4}$ IDA is characterized by microcytic red blood cells, which are relatively pale in color (hypochromic) compared to normal red blood cells, resulting in reduced oxygen delivery to body tissues and decreased activity of enzymes with iron cofactors. ${ }^{2}$ While IDA may be asymptomatic, the reduced oxygen delivery and enzyme activity can result 
in dyspnea, palpitations, weakness, fatigue, and low work productivity, among many other symptoms. ${ }^{2,5}$

IDA is typically diagnosed based on a combination of hemoglobin $(\mathrm{Hb})$ and ferritin levels, with the World Health Organization defining anemia as $\mathrm{Hb}$ concentrations below $13 \mathrm{~g} / \mathrm{dL}(7.7 \mathrm{mmol} / \mathrm{L})$ in men or below $12 \mathrm{~g} / \mathrm{dL}(7.4 \mathrm{mmol} / \mathrm{L})$ in nonpregnant women. ${ }^{6} \mathrm{As} \mathrm{Hb}$ levels alone are not specific for iron deficiency (anemia may be attributed to other causes and mild iron deficiency may not affect $\mathrm{Hb}$ levels), serum ferritin levels are also required for diagnosis. ${ }^{5}$ Serum ferritin concentrations lower than $15 \mu \mathrm{g} / \mathrm{L}$ confirm a diagnosis of ID, while concentrations between 15 and $100 \mu \mathrm{g} / \mathrm{L}$ may be indicative of ID depending on other factors such as chronic inflammation and rheumatoid disease. ${ }^{7}$

The overall management of IDA depends on the etiology; IDA is often a sequela of inflammatory bowel disease (IBD), chronic kidney disease, malabsorption, or chronic blood loss from the genitourinary or gastrointestinal tracts or a consequence of major elective surgeries. ${ }^{8,9}$ Where possible, treatment of the underlying condition is important in patients presenting with IDA, but iron supplementation should also be initiated immediately upon diagnosis. ${ }^{5}$ Oral administration of up to $200 \mathrm{mg}$ elemental iron daily is typically the first-line iron replacement therapy for patients with IDA, but parenteral administration (usually intravenous [IV]) is the preferred first-line therapy in specific patient subgroups, including patients with clinically active IBD, previous intolerance to oral iron, $\mathrm{Hb}$ below $10 \mathrm{~g} / \mathrm{dL}$, or in patients who need erythropoiesis-stimulating agents or rapid iron replenishment. ${ }^{10,11}$ IV iron is also typically used in place of oral iron in patients with significant iron loss or poor absorption of oral iron. In addition to more rapid replenishment of iron stores, and faster and larger increases in $\mathrm{Hb}$, IV iron also has the benefit of improved adherence relative to oral iron. ${ }^{12}$ Furthermore, the incidence of anaphylaxis with early IV iron formulations (high molecular weight iron dextran) has been reduced with newer IV iron formulations, including iron sucrose (Venofer ${ }^{\circledR}$ [IS], Vifor France SA, Victor, France), low molecular weight iron dextran (Cosmofer ${ }^{\circledR}$ [LMWID], Pharmacosmos A/S, Holbaek, Denmark), iron isomaltoside
(Monofer $^{\circledR}$ [IIM], Pharmacosmos A/S), and ferric carboxymaltose $\left(\right.$ Ferinject ${ }^{\circledR}[\mathrm{FCM}]$, Vifor France SA). ${ }^{13}$

Given the wide range of options now available for parenteral iron administration and the widened range of conditions for which IV iron is recommended, ${ }^{14}$ the aim of the present study was to evaluate differences in the cost of administering IIM relative to other IV iron formulations in patients with IDA from the perspective of a UK health care payer (National Health Service [NHS] England).

\section{Methods}

A budget impact model was developed in Microsoft Excel (Microsoft Corporation, Redmond, WA, USA) to evaluate the cost of using IIM relative to FCM, LMWID, and IS in patients with IDA from the perspective of a UK health care payer (NHS England). The analysis was conducted based on the assumption that there are no differences in the efficacy and safety of the iron formulations in addressing the iron deficit, in line with previously published cost-minimization analyses. ${ }^{15}$

\section{Model and scenarios analyzed}

A model was developed to estimate iron deficit using three distinct approaches: a simplified dosing table (Table 1), a population average and standard deviation based on pooled estimates from recent randomized controlled trials (RCTs) in patients with IDA, ${ }^{16}$ and a modified version of the Ganzoni formula (Equation 1). The simplified table approach was adopted for the reference case analyses, as table-based dosing is recommended by the European Crohn's and Colitis Organization for treating patients with IDA associated with IBD, and treatment in line with the Ganzoni formula has been found to result in low $(<100 \mu \mathrm{g} / \mathrm{L})$ serum ferritin levels. ${ }^{10,17}$

Modified Ganzoni formula:

$$
\text { Iron deficit }(\mathrm{mg})=\text { weight }(\mathrm{kg}) \cdot
$$$$
[15-\mathrm{Hb}(\mathrm{g} / \mathrm{dL})] \cdot 2.4+500
$$

In addition to the three methods of estimating iron deficiency in the specified population, the model also incorporated simple models to determine the ability of each

Table I Simplified iron isomaltoside dosing table used in the reference case analysis showing the total recommended iron dose by bodyweight and hemoglobin concentration and the proportions of patients falling into each category

\begin{tabular}{lllll}
\hline & \multicolumn{3}{l}{ Bodyweight } & $\mathbf{2 0 - 7 0 ~} \mathbf{~ k g}$ \\
\cline { 2 - 5 } & & $<\mathbf{5 0} \mathbf{~ k g}^{*}$ & $\mathbf{5 0}$ & $1,500 \mathrm{mg}(17.4 \%)$ \\
\hline $\mathbf{H b}(\mathbf{g} / \mathbf{d L})$ & $\geq 10$ & $1,000 \mathrm{mg}^{*}(1.4 \%)$ & $1,000 \mathrm{mg}(12.3 \%)$ & $2,000 \mathrm{mg}(38.6 \%)$ \\
\hline
\end{tabular}

Note: *Not defined in the summary of product characteristics but assumed to use the same dose as patients weighing $50-70$ kg in the same hemoglobin category. 
comparator to address the iron deficit. IIM and LMWID were able to dose $20 \mathrm{mg} / \mathrm{kg}$, while FCM was able to dose $1,000 \mathrm{mg}$ and IS $200 \mathrm{mg}$ in a single dose, in line with the summaries of product characteristics. ${ }^{18,19}$

Since usage of different iron formulations is likely to differ from region to region, only head-to-head comparisons were conducted in which the "with IIM" scenario consistently assumed $100 \%$ market share for IIM, while the "without IIM" scenarios assumed 100\% market share for LMWID, FCM, and IS in three reference case scenarios. The model was constructed to report the mean number of infusions required per patient, the mean number of patients requiring more than one infusion, the overall and incremental costs in the "with IIM" and "without IIM" scenarios, and the result of an infusion-based number needed to treat (NNT) calculation reporting the NNT with IIM to avoid a single infusion.

\section{Costs, time horizon, and discounting}

In the reference case analysis, costs were evaluated over a 1-year time horizon using health care resource groups (HRGs). HRG costs in the UK are used to calculate the income for individual NHS trusts that is received from NHS commissioners for performing particular treatments or procedures. These values are therefore representative of the ultimate cost of each treatment for the Department of Health. HRGs SA04D and SA04F were employed in the present analysis, denoting IDA with and without complications and corresponding to costs of GBP 385 and GBP 284, respectively. In the reference case, the two HRGs were weighted based on the relative number of finished consultant episodes for each HRG as reported by the Health and Social Care Information Center (HSCIC) in 2014-2015 (23,837 and 22,657 episodes for SA04D and SA04F, respectively). ${ }^{20}$ No market forces factor was applied in the reference case analysis. Discounting was not employed in the reference case as no costs were modeled beyond year 1 and discounting is not recommended in the budget impact modeling guidelines from the International Society for Pharmacoeconomic and Outcomes Research. ${ }^{21}$

\section{Population and cohort characteristics}

Patient characteristics were based on an analysis of seven IDA RCTs included in a recent review. ${ }^{16}$ The base case analysis was conducted in patients with IDA with a mean bodyweight of $82.4 \mathrm{~kg}$ (SD $22.5 \mathrm{~kg}$ ) and Hb levels of $9.99 \mathrm{~g} /$ $\mathrm{dL}$ (SD $1.03 \mathrm{~g} / \mathrm{dL}) .{ }^{16}$ The model distributed the cohort over lognormal distributions of bodyweight and $\mathrm{Hb}$ in line with techniques employed by dosing models in other disease areas (Figure 1). ${ }^{22}$ For the $4.5 \%$ patients falling below the minimum
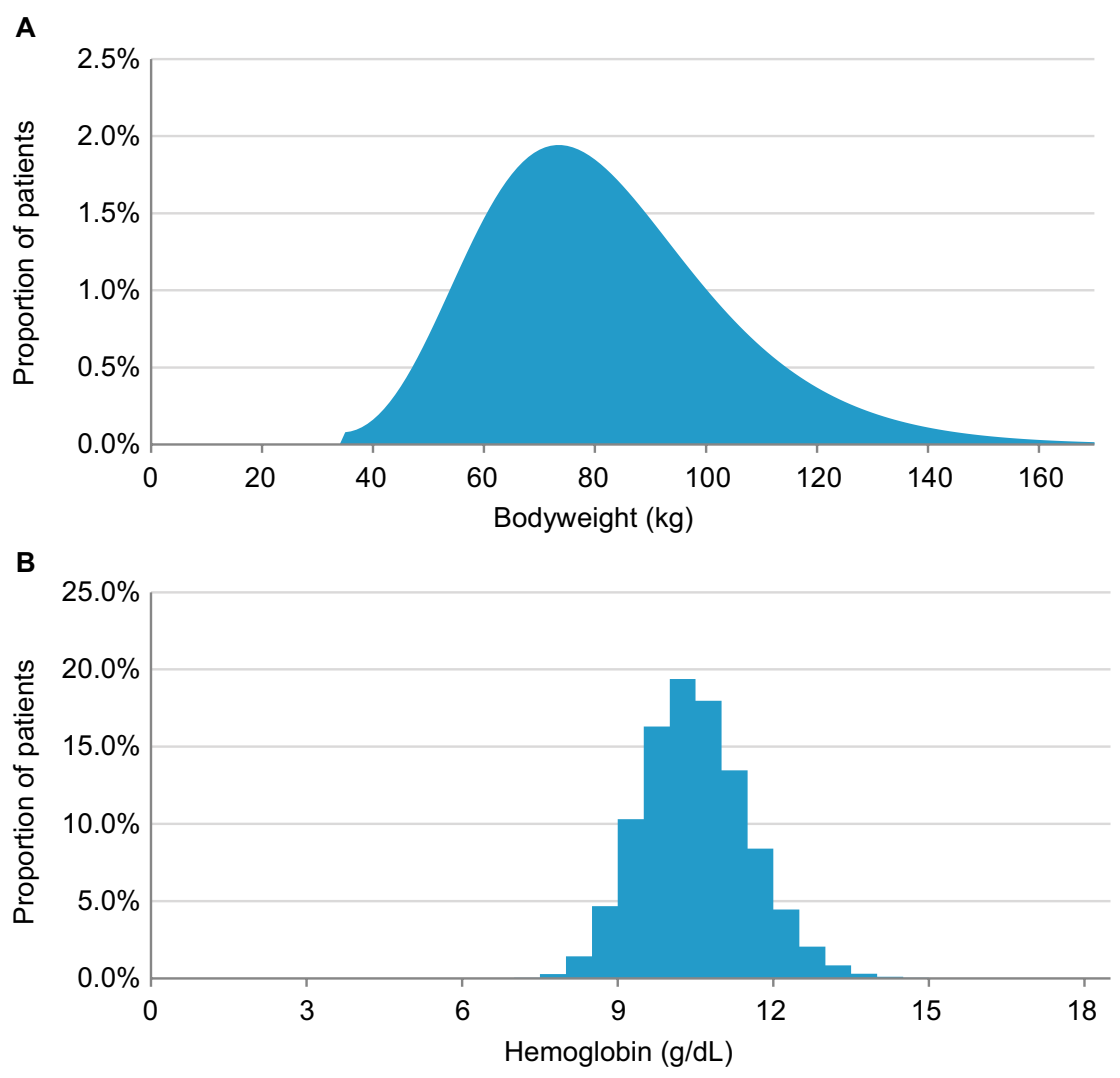

Figure I Histograms of bodyweight and hemoglobin distributions in the base case analysis illustrated using a bodyweight bin size of I kg (A) and a hemoglobin bin size of $0.5 \mathrm{~g} / \mathrm{dL}(\mathbf{B})$. 
weight category in the IIM dosing table (Table 1), patients were assumed to require the same dose as patients in the lowest defined weight category in the same $\mathrm{Hb}$ category. A minimum bodyweight $\left(w_{\min }\right)$ of $35 \mathrm{~kg}$ was assumed in line with the lowest bodyweight threshold listed in the FCM summary of product characteristics. ${ }^{18}$ To avoid crude truncation of the distribution, the probability density function (PDF) was "mirrored" around $w_{\min }$ such that the final PDF was modeled as in Equation 2, in which $\ln N\left(w, \mu, \sigma^{2}\right)$ is the PDF of the lognormal distribution.

Truncated lognormal distribution probability density function:

$$
\begin{aligned}
& \ln N\left(w ; \mu, \sigma^{2}, w_{\min }\right)= \\
& \begin{cases}0 & w<w_{\text {min }} \\
\ln N\left(w ; \mu, \sigma^{2}\right)+\ln N\left(2 w_{\text {min }}-w ; \mu, \sigma^{2}\right) & w \geq w_{\text {min }}\end{cases}
\end{aligned}
$$

The primary analysis reported estimated average costs per patient, but analyses were also conducted for an average clinical commissioning group (CCG). The population size was based on the CCG average for England, which covers 257,400 patients. $^{23}$ The size of the prevalent IDA population was then calculated on the basis of $3 \%$ of males and $8 \%$ of females having IDA, for an average absolute CCG-level prevalence of 14,157 patients with IDA of any etiology. ${ }^{3} \mathrm{Of}$ the IDA patients, the proportion treated with IV iron was based on a market report on global IV iron that reported that 600,000 of 4.5 million IDA patients were treated with IV iron and the remainder with oral iron, corresponding to $13.3 \%$ of all IDA patients receiving IV treatment. ${ }^{24}$ In an average $\mathrm{CCG}$, this resulted in an estimated 1,888 patients receiving IV iron. Given the 1-year analysis time horizon, the reference case analysis included the simplifying assumption that each of the 1,888 patients would require a single course of IV iron treatment over the analysis.

\section{Sensitivity analyses}

A range of one- and multi-way sensitivity analyses were conducted around the reference case analyses. Mean bodyweight assumptions were changed from the base case assumption of $82.36 \mathrm{~kg}$ to a series of lognormal distributions with expected values of $65,70,75,80$, and $85 \mathrm{~kg}$ with assumed standard deviations of $25 \%$ of the mean. The simplified table-based dosing approach used in the reference case was also switched for the modified Ganzoni formula (Equation 1) and a mean iron deficit modeling approach based on a pooled mean and standard deviation from the seven RCTs included in a recent review by Koch et al. ${ }^{16}$ Finally, the HRG casemix was switched to $100 \%$ SA04D (IDA with complications) and $100 \%$ SA04F (IDA without complications) from the HSCIC casemix in the base case analysis.

\section{Results}

Using IIM required 1.3 infusions per patient to correct the mean iron deficit, compared with $1.3,1.8$, and 7.7 with LMWID, FCM, and IS, respectively (Figure 2A). Patients using IIM required multiple infusions in $35 \%$ of cases, compared with $35 \%, 77 \%$, and $100 \%$ of patients with LMWID, FCM, and IS, respectively (Figure 2B). Based on a HRGbased costing methodology, total costs were estimated to be GBP 451 per patient with IIM or LMWID, relative to GBP 594 with FCM or GBP 2,600 with IS, corresponding to savings of $24 \%$ and $83 \%$ with IIM relative to FCM and IS, respectively (Table 2). The NNT to avoid a single infusion with IIM was 2.35 relative to FCM and 0.16 relative to IS; no infusions would be avoided by using IIM in place of LMWID.

Over an average CCG population of 1,888 patients with IDA, costs with IIM were estimated to be GBP $852 \mathrm{k}$ compared with GBP 1.12 million with FCM and GBP 4.91 million with IS, corresponding to average absolute cost savings of GBP 270k with IIM relative to FCM and GBP 4.06 million with IIM relative to IS in a single CCG over 1 year.

Sensitivity analysis showed that assumptions around cohort bodyweight did not affect the directionality of the outcomes, but did have a notable outcome on the magnitude of the cost savings (Figure 3A and B). Specifically, cost savings with IIM increased with increasing mean cohort weight. Switching from the reference case iron deficit calculation approach based on a simplified dosing table to a population mean approach and the Ganzoni formula had mixed effects on the magnitude of the cost savings depending on the comparator (Table 3). Using the Ganzoni formula increased the cost savings with IIM relative to FCM to GBP 248 or $37 \%$ (from savings of GBP 143 or $24 \%$ in the base case), but fractionally decreased the cost savings relative to IS to GBP 2,142 (84\%) from GBP 2,149 (83\%) in the base case. Similarly, the average iron deficit-based approach increased cost savings relative to FCM to GBP 181 (28\%) from GBP $143(24 \%)$ in the base case, while decreasing savings relative to IS to GBP 2,067 or $82 \%$ (from GBP 2,149 or $83 \%$ in the base case). Switching the HRG casemix to $100 \%$ SA04D increased the cost savings proportionally to the higher cost (GBP 385 relative to the weighted average of GBP 336 in the base case), while switching to $100 \%$ SA04F reduced cost savings proportionally (Table 3 ). 
A

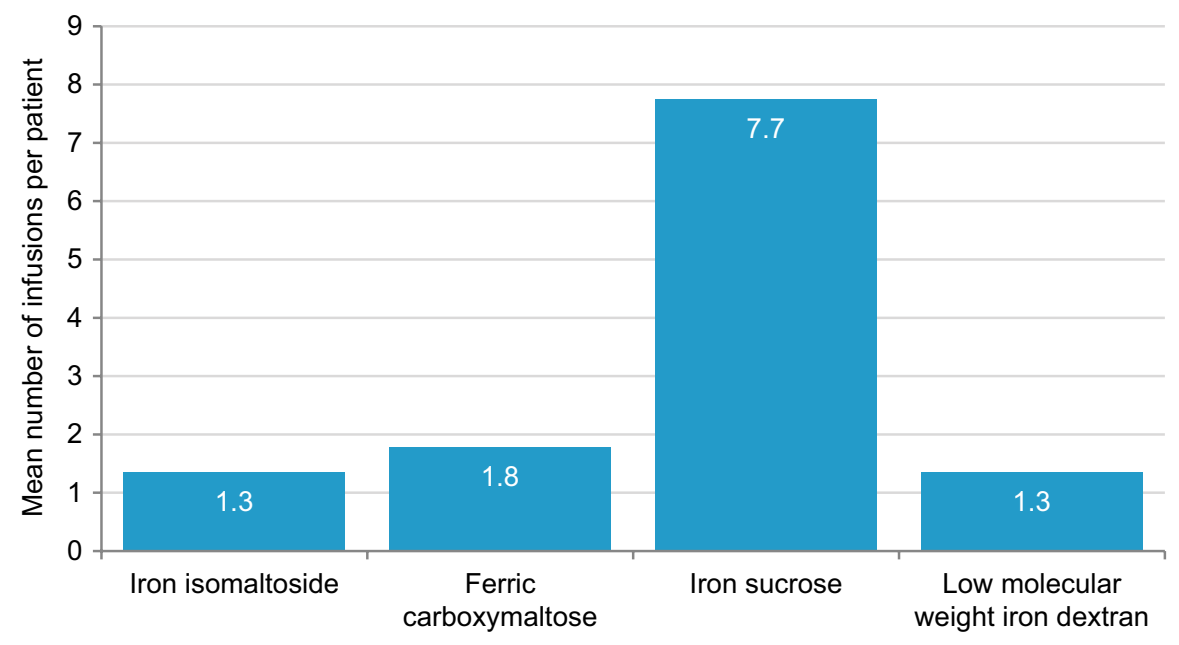

B

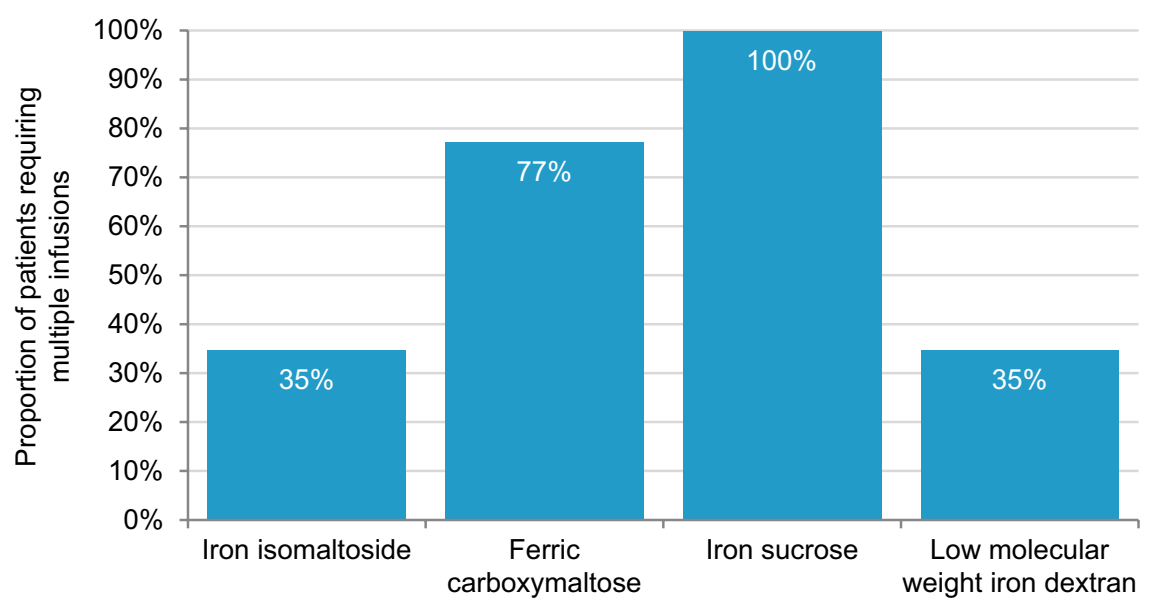

Figure 2 Mean number of infusions per patient (A) and proportion of patients requiring multiple infusions (B).

Table 2 Base case budget impact outcomes expressed as the cost per treated patient per year

\begin{tabular}{llll}
\hline Intravenous iron formulation & HRG-based cost (GBP) & \multicolumn{2}{l}{ Incremental cost of IIM } \\
\cline { 3 - 4 } & & GBP & \% \\
\hline Iron isomaltoside & $45 I$ & -143 & - \\
Ferric carboxymaltose & 594 & $-2,149$ & -24 \\
Iron sucrose & 2,600 & 0 & -83 \\
Low molecular weight iron dextran & 451 & 0 & \\
\hline
\end{tabular}

Abbreviations: GBP, 2016 pounds sterling; HRG, health care resource group; IIM, iron isomaltoside.

\section{Discussion}

Using IIM or LMWID in place of FCM or IS resulted in a marked reduction in the number of infusions required to correct iron deficits in patients with IDA. While the modeled outcomes were directionally in agreement with previous studies, the modeled estimates of the absolute number of repeat visits required with IIM differed from previous studies. A recent Scandinavian observational study of IIM treatment in patients with IBD, the Non-Interventional
Monofer (NIMO) Study, reported a repeat visit rate of 5\% compared with $34 \%$ in the present modeling analysis. ${ }^{25}$ The mean iron dose administered in the study was $1,010 \mathrm{mg}$, which the authors noted was below the average of $1,363 \mathrm{mg}$ that would have been administered if adhering to the simplified dosing table and even below the $1,100 \mathrm{mg}$ that would have been administered in line with the Ganzoni formula, which itself already underestimates the recommended iron dose in patients with IBD. Furthermore, $27 \%$ of patients 

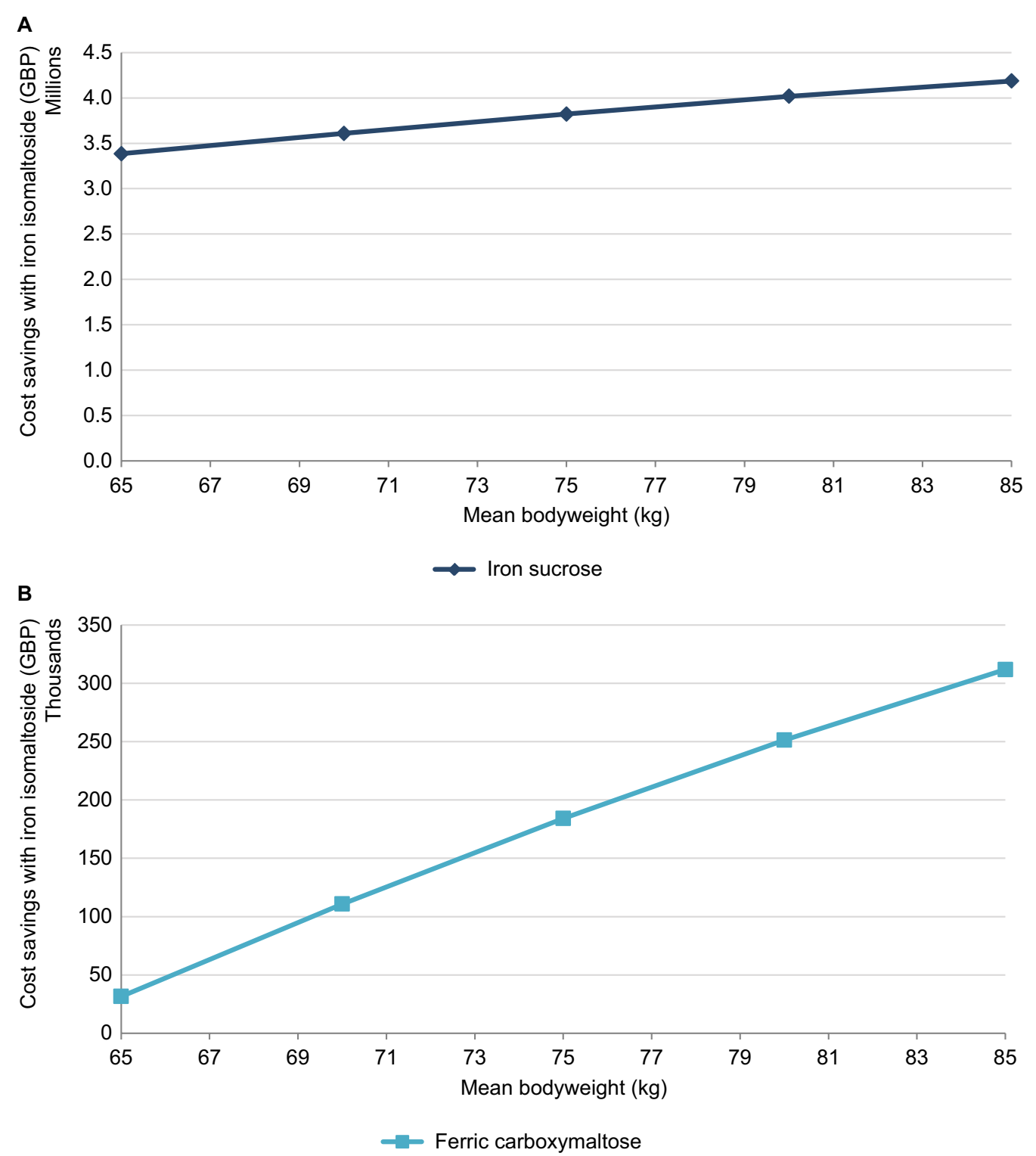

Figure 3 Cost savings with iron isomaltoside relative to iron sucrose (A) and ferric carboxymaltose (B) over a range of mean bodyweights in an average clinical commissioning group.

Abbreviation: GBP, 2016 pounds sterling.

Table 3 One-way sensitivity analyses around the base case analysis

\begin{tabular}{llllllll}
\hline Analysis & $\begin{array}{l}\text { IIM costs } \\
\text { (GBP) }\end{array}$ & $\begin{array}{l}\text { FCM costs } \\
\text { (GBP) }\end{array}$ & $\begin{array}{l}\text { IIM difference } \\
\text { (GBP) }\end{array}$ & $\begin{array}{l}\text { IS costs } \\
\text { (GBP) }\end{array}$ & $\begin{array}{l}\text { IIM difference } \\
\text { (GBP) }\end{array}$ & $\begin{array}{l}\text { LMWID costs } \\
\text { (GBP) }\end{array}$ & $\begin{array}{l}\text { IIM difference } \\
\text { (GBP) }\end{array}$ \\
\hline Base case & 451 & 594 & -143 & 2,600 & $-2,149$ & $45 I$ & 0 \\
Ganzoni formula-based dosing & 419 & 667 & -248 & 2,562 & $-2,142$ & 419 & 0 \\
Average iron deficit-based dosing & 464 & 646 & -181 & 2,531 & $-2,067$ & 464 & 0 \\
HRG mix to 100\% SA04D & 518 & 681 & -164 & 2,981 & $-2,463$ & 518 & 0 \\
HRG mix to 100\% SA04F & 382 & 503 & -121 & 2,199 & $-1,817$ & 503 & 0 \\
\hline
\end{tabular}

Abbreviations: FCM, ferric carboxymaltose; GBP, 2016 pounds sterling; HRG, health care resource group; Hb, hemoglobin; IIM, iron isomaltoside; IS, iron sucrose; LMWID, low molecular weight iron dextran.

still had anemia after treatment, suggesting that dosing in routine clinical practice was insufficient to fully address the iron deficiency. The present analysis modeled scenarios in which all patients received exactly the dose recommended by either the Ganzoni formula or the simplified dosing table approaches, which would explain the discrepancy in the repeat visit estimates. Other recent data from NIMO have shown higher initial iron dosing to be prudent in terms of 
reducing the number of retreatments, with patients receiving doses $>1,000 \mathrm{mg}$ having $65 \%$ lower odds of needing iron retreatment than patients receiving $1,000 \mathrm{mg}(p=0.001){ }^{26}$

Relatedly, the present analysis did not capture any degree of clinical discretion in determining the need for subsequent visits. For instance, in a patient with a bodyweight of $74 \mathrm{~kg}$ and $\mathrm{Hb}$ level of $10 \mathrm{~g} / \mathrm{dL}$, the simplified dosing tables for IIM or FCM both specify an iron requirement of $1,500 \mathrm{mg}$. At an IIM dose of $20 \mathrm{mg} / \mathrm{kg}$, a maximum of 1,480 mg of iron could be administered to the patient and the model would therefore report a requirement of two infusions. In practice, the clinician would likely decide that a dose of $1,480 \mathrm{mg}$ (98.7\% of the calculated requirement) would be sufficient and that no subsequent infusion would be required. This effect was consistently applied across the four iron formulations and hence would be unlikely to drive any substantive incremental differences between comparators, but means that the absolute number of infusions modeled is likely to represent an overestimate relative to routine clinical practice.

Finally, the model assumed that all IV iron formulations were equally effective at rectifying the iron deficiency. This assumption was a corollary of the assumption that all iron formulations were dosed equivalently over the full course of infusions and all patients therefore received the same modeled dose of iron. In clinical practice, however, practical aspects of administration may result in different effectiveness outcomes. In particular, the number of infusions required with IS may ultimately present a barrier to administration of the full dose; a twice-weekly $200 \mathrm{mg}$ infusion regimen would take 5 weeks to administer $2,000 \mathrm{mg}$ compared to 1 week with IIM or FCM, increasing the risk of nonadherence to the full dose. Indeed, this phenomenon has been observed in RCTs of FCM versus IS $(92.5 \%$ vs $79.1 \%$ adherence, respectively, $p<0.001) .{ }^{27}$ In addition to the equivalent efficacy assumption, the present analysis also assumed that the formulations were equivalent in terms of safety. This is in line with previous cost-minimization analyses in IDA. ${ }^{28}$

While the present study represents the first published budget impact analysis of IIM in IDA from a national payer perspective, a previous study has reported findings of a costminimization analysis of IIM in the UK hospital setting, ${ }^{15,29}$ and previous analyses of the budget impact of parenteral iron have broadly agreed with the findings of the present analysis with regard to FCM, IS, and LMWID. In 2014, Brock et al published the findings of a budget impact analysis of IS versus FCM in Switzerland, finding that switching patients to FCM was associated with cost savings of $30 \%-44 \%$ per patient per treatment cycle relative to IS. ${ }^{30}$ This compares to a reduction of $77 \%$ in the present analysis, with the discrepancy likely being driven by the real-world nature of the patient data in Brock et al. More recently, Calvet et al published a cost-minimization analysis of FCM, IS, and oral iron in patients with colon cancer and IDA in Spain, reporting total costs per patient (including costs of iron infusion, transfusion, and hospitalization) of EUR 1,827 with FCM, EUR 2,312 with IS, and EUR 2,101 for oral iron. ${ }^{31}$ The EUR 485 (21\%) cost savings with FCM relative to IS were driven by reduced hospitalization costs. The lower cost savings with FCM relative to IS compared to the present analysis may have been driven by the lower cost per hour of health care professional time in the Spanish setting relative to the UK. High-dose administration of iron has previously been shown to reduce waiting lists by increasing patient throughput. ${ }^{32}$ The reductions in infusions modeled in the present analysis with IIM relative to other IV iron formulations show that improvements in patient throughput could also be achieved through the use of different IV iron formulations. Specifically, treating 2.35 IDA patients with IIM rather than FCM would result in one avoided infusion, while treating 0.16 patients with IIM in place of IS would achieve the same result, with 6.4 fewer infusions being required per patient switched. Furthermore, the improvements would be accompanied by substantial reductions in the direct costs of treatment, saving GBP 143 per patient relative to FCM and GBP 2,149 relative to IS over 1 year. The comparison of IIM with LMWID yielded the same modeled estimates of infusion requirements and therefore the same HRG-based cost estimates; however, the use of HRG-based cost estimates masked the burden placed on NHS infusion facilities by LMWID and indeed the inconvenience and lost productivity experienced by patients prescribed LMWID. ${ }^{13,29}$ While the same maximum dose can be administered in a single infusion with LMWID and IIM, LMWID must be administered under careful observation over the course of the $4-6$ hour infusion, ${ }^{33}$ whereas IIM doses of $<1,000 \mathrm{mg}$ can be administered over more than 15 minutes and doses $>1,000 \mathrm{mg}$ can be administered in 30 minutes or more, resulting in a substantial increase in infusion facility capacity with IIM relative to LMWID.

When considering the overall effect of the reductions in the number of infusions required, the perspective of the present analysis should be taken into consideration. Notably, the health care payer perspective and the exclusive use of HRG-based cost estimates yield an analysis that is likely 
to be highly conservative relative to other perspectives. A similar analysis conducted from the societal perspective, for example, would also capture indirect costs borne by other payers, such as patient transportation costs and infusion center running costs, in addition to costs associated with lost workplace productivity arising from infusion center visits.

\section{Conclusion}

Using IIM or LMWID in place of FCM or IS resulted in a marked reduction in the number of infusions required to correct iron deficits in patients with IDA, with just $35 \%$ of patients requiring multiple infusions with IIM relative to $77 \%$ and $100 \%$ with FCM and IS, respectively. The reduction in infusions was accompanied by reductions in cost of $24 \%$ and $83 \%$ with IIM relative to FCM and IS over 1 year, respectively. Based on an HRG-based costing of IV iron therapies, IIM or LMWID would incur equivalent costs from the UK payer perspective. The substantially shorter infusion times with IIM confer advantages over LMWID from the care provider perspective with IIM, therefore representing the most economical IV treatment option when considering both costs from the national payer perspective and resource utilization from the care provider perspective.

\section{Acknowledgment}

This work was supported by a grant from Pharmacosmos A/S.

\section{Disclosure}

Gorden Muduma is a full-time employee of Pharmacosmos $\mathrm{A} / \mathrm{S}$, the EU marketing authorization holder for Monofer ${ }^{\circledR}$ (IIM) and Cosmofer ${ }^{\circledR}$ (LMWID). Richard Pollock is a full-time employee of Ossian Health Economics and Communications $\mathrm{GmbH}$, which received consultancy fees from Pharmacosmos A/S to develop the budget impact model and conduct the analysis. The authors report no other conflicts of interest in this work.

\section{References}

1. Kassebaum NJ, Jasrasaria R, Naghavi M, et al. A systematic analysis of global anemia burden from 1990 to 2010. Blood. 2014;123:615-624.

2. Camaschella C. Iron-deficiency anemia. N Engl J Med. 2015;372(19): 1832-1843.

3. BMJ Best Practice. Iron deficiency anaemia. Epidemiology. Available from: http://bestpractice.bmj.com/best-practice/monograph/94/basics/ epidemiology.html. Accessed January 17, 2017.

4. Looker AC, Dallman PR, Carroll MD, Gunter EW, Johnson CL. Prevalence of iron deficiency in the United States. JAMA. 1997;277(12): 973-976.

5. National Institute for Health and Care Excellence. Clinical Knowledge Summaries. Anaemia - Iron Deficiency. London; 2013. Available from: https://cks.nice.org.uk/anaemia-iron-deficiency. Accessed February $15,2017$.
6. WHO. Haemoglobin Concentrations for the Diagnosis of Anaemia and Assessment of Severity. Vitamin and Mineral Nutrition Information System. Geneva: World Health Organization; 2011. Available from: http://www. who.int/vmnis/indicators/haemoglobin.pdf. Accessed March 30, 2017.

7. Guyatt GH, Oxman AD, Ali M, Willan A, Mcllroy W, Patterson C. Laboratory diagnosis of iron-deficiency anemia: an overview. $J$ Gen Intern Med. 1992;7(2):145-153.

8. Johnson-Wimbley TD, Graham DY. Diagnosis and management of iron deficiency anemia in the 21 st century. Therap Adv Gastroenterol. 2011;4(3):177-184.

9. NHS Blood and Transplant. National Comparative Audit of Blood Transfusion. Available from: http://hospital.blood.co.uk/audits/nationalcomparative-audit/. Accessed March 31, 2017.

10. Dignass AU, Gasche C, Bettenworth D, et al; European Crohn's and Colitis Organisation [ECCO]. European consensus on the diagnosis and management of iron deficiency and anaemia in inflammatory bowel diseases. J Crohns Colitis. 2015;9(3):211-222.

11. Goddard AF, James MW, McIntyre AS, Scott BB; British Society of Gastroenterology. Guidelines for the management of iron deficiency anaemia. Gut. 2011;60(10):1309-1316.

12. Bayraktar UD, Bayraktar S. Treatment of iron deficiency anemia associated with gastrointestinal tract diseases. World J Gastroenterol. 2010;16(22):2720-2725.

13. Cançado RD, Muñoz M. Intravenous iron therapy: how far have we come? Rev Bras Hematol Hemoter. 2011;33(6):461-469.

14. Richards T, Clevenger B, Keidan J, et al. PREVENTT: preoperative intravenous iron to treat anaemia in major surgery: study protocol for a randomised controlled trial. Trials. 2015;16:254.

15. Bhandari S. Update of a comparative analysis of cost minimization following the introduction of newly available intravenous iron therapies in hospital practice. Ther Clin Risk Manag. 2011;7:501-509.

16. Koch TA, Myers J, Goodnough LT. Intravenous iron therapy in patients with iron deficiency anemia: dosing considerations. Anemia. 2015;2015:763576.

17. Kulnigg S, Stoinov S, Simanenkov V, et al. A novel intravenous iron formulation for treatment of anemia in inflammatory bowel disease: the ferric carboxymaltose (FERINJECT) randomized controlled trial. Am J Gastroenterol. 2008;103(5):1182-1192.

18. electronic Medicines Compendium (eMC). Ferinject (ferric carboxymaltose) - summary of product characteristics. Available from: https:// www.medicines.org.uk/emc/medicine/24167. Accessed March 2, 2017.

19. electronic Medicines Compendium (eMC). Venofer (iron sucrose) - summary of product characteristics. Available from: https://www. medicines.org.uk/emc/medicine/24168. Accessed March 2, 2017.

20. The Health and Social Care Information Centre. Hospital Episode Statistics for England: Healthcare Resource Groups - HRG version 4. Available from: http://content.digital.nhs.uk/hes. Accessed March 2, 2017.

21. Sullivan SD, Mauskopf JA, Augustovski F, et al. Budget impact analysisprinciples of good practice: report of the ISPOR 2012 Budget Impact Analysis Good Practice II Task Force. Value Health. 2014;17(1):5-14.

22. Pollock RF, Kappelgaard AM, Seitz L. An analysis of product wastage arising from dosing increment granularity in four modern growth hormone administration devices. Expert Opin Drug Deliv. 2015;12(3):353-360.

23. Office for National Statistics. Annual Small Area Population Estimates: Mid-2014 and Mid-2013. Available from: https://www.ons. gov.uk/peoplepopulationandcommunity/populationandmigration/ populationestimates/bulletins/annualsmallareapopulationestimates/ mid2014andmid2013. Accessed March 31, 2017

24. AMAG Pharmaceuticals Inc. AMAG Analyst Day 2016. SEC 8-K Filing 2016. Exhibit 99.1. Available from: https://www.sec.gov/Archives/ edgar/data/792977/000110465916124649/a16-12443_1ex99d1.htm. Accessed February 22, 2017.

25. Frigstad SO, Rannem T, Hellstrom PM, Hammarlund P, Bonderup O. A Scandinavian prospective observational study of iron isomaltoside 1000 treatment: clinical practice and outcomes in iron deficiency anaemia in patients with IBD. Poster P481 presented at: 10th Congress of the European Crohn's and Colitis Organisation (ECCO); February 8-21, 2015; Barcelona, Spain. 
26. Frigstad SO, Hammarlund $\mathrm{P}$, Bonderup $\mathrm{O}$, et al. Anaemia and iron deficiency in gastroenterology: a Scandinavian prospective, observational study of iron isomaltoside in clinical practice. Abstract and poster P533 presented at: The 12th Congress of the European Crohn's and Colitis Organisation (ECCO); February 15-18 2017; Barcelona, Spain.

27. Evstatiev R, Marteau P, Iqbal T, et al; FERGI Study Group. FERGIcor, a randomized controlled trial on ferric carboxymaltose for iron deficiency anemia in inflammatory bowel disease. Gastroenterology. 2011;141(3):846--853.e1-2.

28. Calvet X, Ruíz MÀ, Dosal A, et al. Cost-minimization analysis favours intravenous ferric carboxymaltose over ferric sucrose for the ambulatory treatment of severe iron deficiency. PLOS ONE. 2012;7(9):e45604.

29. Bhandari S. A hospital-based cost minimization study of the potential financial impact on the UK health care system of introduction of iron isomaltoside 1000. Ther Clin Risk Manag. 2011;7:103-13.
30. Brock E, Braunhofer P, Troxler J, Schneider H. Budget impact of parenteral iron treatment of iron deficiency: methodological issues raised by using real-life data. Eur J Health Econ. 2014;15(9):907-916.

31. Calvet X, Gené E, Ruíz MÀ, et al. Cost-minimization analysis favours intravenous ferric carboxymaltose over ferric sucrose or oral iron as preoperative treatment in patients with colon cancer and iron deficiency anaemia. Technol Health Care. 2016;24(1):111-120.

32. Gozzard D. When is high-dose intravenous iron repletion needed? Assessing new treatment options. Drug Des Devel Ther. 2011;5: 51-60.

33. electronic Medicines Compendium (eMC). CosmoFer (Iron(III)hydroxide dextran complex) - summary of product characteristics. Available from: https:/www.medicines.org.uk/emc/medicine/14139. Accessed March 2, 2017.

\section{ClinicoEconomics and Outcomes Research}

\section{Publish your work in this journal}

ClinicoEconomics and Outcomes Research is an international, peerreviewed open-access journal focusing on health technology assessment, pharmacoeconomics and outcomes research in the areas of diagnosis, medical devices, and clinical, surgical and pharmacological intervention. The economic impact of health policy and health systems
Submit your manuscript here: https://www.dovepress.com/clinicoeconomics-and-outcomes-research-journal

organization also constitute important areas of coverage. The manuscript management system is completely online and includes a very quick and fair peer-review system, which is all easy to use. Visit http://www.dovepress.com/testimonials.php to read real quotes from published authors. 